\title{
Genetic and mutational heterogeneity of autosomal recessive chronic granulomatous disease in Tunisia
}

\author{
R. El Kares $\cdot$ M. R. Barbouche $\cdot$ H. Elloumi-Zghal $\cdot$ M. Bejaoui $\cdot$ J. Chemli $\cdot$ \\ F. Mellouli · N. Tebib - M. S. Abdelmoula $\cdot$ S. Boukthir $\cdot$ Z. Fitouri $\cdot$ S. M'Rad \\ K. Bouslama $\cdot$ H. Touiri $\cdot$ S. Abdelhak $\cdot$ M. K. Dellagi
}

Received: 3 April 2006/Accepted: 12 July 2006/ Published online: 26 August 2006

(C) The Japan Society of Human Genetics and Springer-Verlag 2006

\begin{abstract}
NADPH oxidase, a multi-subunit protein consisting of cytosolic components and the membranebound heterodimer,plays an instrumental role in host defence mechanisms of phagocytes. Genetic deficiency of the enzymatic complex results in an inherited disorder, chronic granulomatous disease (CGD), which is characterized by an impaired phagocyte microbicidal
\end{abstract}

R. El Kares · S. Abdelhak $(\varangle)$

Molecular Investigation of Genetic Orphan Diseases

Research Unit (MIGOD), Institut Pasteur de Tunis, BP 74,

13 Place Pasteur 1002, Tunis, Tunisia

e-mail: sonia.abdelhak@pasteur.rns.tn

M. R. Barbouche $\cdot$ H. Elloumi-Zghal · M. K. Dellagi

Laboratory of Immunopathology,

Vaccinology and Molecular Genetics,

Institut Pasteur de Tunis, Tunis, Tunisia

M. Bejaoui · F. Mellouli

Centre National de Greffe de Moelle Osseuse, Tunis,

Tunisia

J. Chemli

Service de Pédiatrie,

Centre Hospitalo-Universitaire Sahloul, Sousse, Tunisia

N. Tebib · M. S. Abdelmoula

Service de Pédiatrie, Hôpital La Rabta, Tunis, Tunisia

S. Boukthir $\cdot$ Z. Fitouri

Hôpital d'Enfants, Tunis, Tunisia

S. M'Rad · K. Bouslama

Hôpital Mongi Slim, La Marsa, Tunisia

H. Touiri

Service des maladies infectieuses, Hôpital La Rabta, Tunis, Tunisia activity. X-Linked (XL) CGD results from a mutation in the $C Y B B$ gene encoding the gp91phox subunit, while autosomal recessive (AR) CGD is associated with mutations in one of the NCF1, NCF2 and CYBA genes that encode the p47phox, p67phox and p22phox subunits, respectively. In the study reported here, we investigated genetic defects underlying CGD in 15 Tunisian patients from 14 unrelated families. Haplotype analyses and homozygosity mapping with microsatellite markers around known CGD genes assigned the genetic defect to $N C F 1$ in four patients, to $N C F 2$ in four patients and to $C Y B A$ in two patients. However, one family with two CGD patients seemed not to link the genetic defect to any known AR-CGD genes. Mutation screening identified two novel mutations in $N C F 2$ and $C Y B A$ in addition to the recurrent mutation, $\triangle \mathrm{GT}$, in $N C F 1$ and a splice site mutation previously reported in a North African patient. Our results revealed the genetic and mutational heterogeneity of the AR recessive form of CGD in Tunisia.

Keywords Autosomal recessive $\cdot$ Chronic granulomatous disease $\cdot$ Consanguinity $\cdot$ Homozygosity mapping $\cdot$ Mutation screening

\section{Introduction}

NADPH oxidase is the key enzyme for the inducible production of superoxide $\left(\mathrm{O}_{2}^{-}\right)$and superoxide-derived reactive oxygen species in phagocytes and plays a crucial role in host defence mechanisms against microbial infection. The fully assembled active NADPH oxidase complex comprises membrane-bound and cytosolic components. The membrane-associated 
core of the oxidase consists of a heterodimeric $b$-type cytochrome composed of light- (p22phox) and heavy(gp91phox) chain polypeptides. The cytosolic components include p67phox, p47phox, p40phox and the small GTPase protein, Rac 2 (Heyworth et al. 1994). When invasive microorganisms are sequestered in phagocyte phagolysozomes, the cytosolic subunits are translocated to the membrane surface and adjoined with the membrane-bound subunits, thereby creating the activated complex (Babior 1999). Activated $\mathrm{NADPH}$ oxidase then catalyses the production of superoxide, which in turn generates microbicidal reactive oxygen molecules in the phagocytic vesicles. The failure to produce superoxide impedes the killing of microbial pathogens and exposes the host to recurrent, life-threatening infections.

Chronic granulomatous disease (CGD) is a rare inherited disorder of the innate immune system caused by genetic defects in the superoxide-generating NADPH oxidase of phagocytes (Dinauer and Orkin 1992). The incidence of CGD is about 1 in 250,000 $1,000,000$ individuals, with reported frequencies varying greatly in different countries (Roos et al. 1993; Ahlin et al. 1995). Defects in the genes encoding four components of the phox complex (gp91phox, p22phox, p47phox and p67phox) are known to cause CGD (Royer-Pokora et al. 1986; Dinauer et al. 1987; Clark et al. 1989).

Although p40phox has been strongly implicated in NADPH oxidase regulation, to date no specific disorder has been recognized to be the result of mutations in the NCF4 gene encoding p40phox. However, p40phox levels have been reported to be reduced in p67phoxdeficient CGD (Wientjes et al. 1993; Tsunawaki et al. 1994). In addition, no genetic defects in Rac 2 have been reported so far, although such a defect might produce a lethal phenotype or that the closely related Rac 1, which is present in phagocytes, might compensate for any loss of Rac 2 (Knaus et al. 1991; Kwong et al. 1993).

The most common form of CGD (approximately $65 \%$ ) is the $\mathrm{X}$-linked (XL) form, which is due to defects in the $C Y B B$ gene coding for gp91phox; only males are affected by the XL form (Roos et al. 1996). About one third of all reported cases are inherited in an autosomal recessive (AR) manner and thus expressed in both males and females. The mutation affecting the p22phox subunit (CYBA, located at $16 \mathrm{q} 24)$ accounts for about $6 \%$ of all CGD cases, while approximately $5 \%$ are caused by mutations in the gene for p67phox (NCF2, 1q25). The most common form of AR-CGD (about $24 \%$ of all cases) is caused by mutations in the gene for p47phox (NCF1, 7q11.23)
(Cross et al. 2000). Unlike the other AR and XL forms of the disease, in which there is a great heterogeneity among mutations, a single defect accounts for the vast majority of p47phox-deficiency - a GT deletion $(\Delta \mathrm{GT})$ at the beginning of exon 2 of NCF1 (Casimir et al. 1991; Roesler et al. 2000). The high incidence of this single mutation is most likely caused by recombination events between the functional $N C F 1$ and at least one of the presumable pseudogenes ( $\Psi N C F 1$ ); these pseudogenes contain the GT deletion and are closely linked to NCF1 (Gorlach et al. 1997; Roesler et al. 2000).

To our knowledge no extensive molecular investigation of CGD has been reported for the North African population. In Tunisia, a retrospective study consisting of clinical observations of 14 CGD patients from 12 families described a high rate of female patients (nine boys and five girls) and consanguinity $(75 \%)$ as well as several deaths in early childhood of male and female infants. Consequently, this study may suggest a relatively high prevalence of AR forms among Tunisian CGD patients (Barbouche et al. 1999).

We report here a genetic investigation of CGD in Tunisian patients. We also show the usefulness of haplotype classification by homozygosity mapping of patients born as a result of consanguineous marriages, the latter being a custom culturally favoured in Southern Mediterranean countries.

\section{Patients and methods}

Patients

Fifteen patients that originated from various geographic locations in Tunisia were investigated (Table 1). Eight of the 15 patients $(53 \%)$ are the offspring of consanguineous marriages; three patients were males who were not the offspring of consanguineous marriages. All of the patients underwent extensive clinical and laboratory investigations. The diagnosis of CGD was based on the absence of nitroblue tetrazolium (NBT) reduction by the patients' neutrophils (Baehner and Nathan 1967).

\section{Establishment of B lymphoblastoid cell lines}

B lymphoblastoid cell lines derived by Epstein-Barr virus infection (EBV-B LCL) express all of the constituents of NADPH-oxidase. As in neutrophils, the oxidase activity of EBV-B LCL has been shown to be defective in the different forms of CGD; consequently, these cells can be used as a model to study the genetic 
Table 1 Characteristics of the CGD patients studied in this report

\begin{tabular}{|c|c|c|c|c|c|c|}
\hline Patients & Sex & Age & $\begin{array}{l}\text { Familial history } \\
\text { of death in } \\
\text { early infancy }\end{array}$ & $\begin{array}{l}\text { Consanguinity } \\
\text { of parents }\end{array}$ & Responsible gene & Mutation \\
\hline CGD-84 & $\mathrm{F}$ & 3 months & Negative & First-degree cousins & NCF1 & $\Delta \mathrm{GT}$ \\
\hline CGD-285 & $\mathrm{F}$ & 11 years & Negative & First-degree cousins & $N C F 1$ & $\Delta \mathrm{GT}$ \\
\hline CGD-109 & $\mathrm{F}$ & 2 years & $\mathrm{ND}^{\mathrm{a}}$ & Uncertain & $N C F 1$ & $\Delta \mathrm{GT}$ \\
\hline CGD-250 & $\mathrm{F}$ & 2 years and 8 months & Positive & Uncertain & NCF1 & $\Delta \mathrm{GT}$ \\
\hline CGD-350 & M & 20 years & ND & None & $N C F 1$ & $\Delta \mathrm{GT}$ \\
\hline CGD-17 & M & 10 months & Positive & First-degree cousins & $N C F 2$ & N419I \\
\hline CGD-193 & M & 19 months & Positive & First-degree cousins & $N C F 2$ & $\mathrm{IV} 3+2 \mathrm{~T}>\mathrm{C}$ \\
\hline CGD-222 & $\mathrm{F}$ & 3 years & Negative & First-degree cousins & $N C F 2$ & ND \\
\hline CGD-191 & M & 2 years & Positive & Second-degree cousins & $N C F 2$ & ND \\
\hline CGD-275 & M & 18 months & ND & Uncertain & $C Y B A$ & 295-301delGTGCCCG \\
\hline CGD-65 & M & 9 months & ND & Uncertain & $C Y B A$ & ND \\
\hline CGD-5 & $\mathrm{F}$ & 7 years & Positive & First-degree cousins & Another AR-CGD ${ }^{\mathrm{b}}$ & ND \\
\hline CGD-346 & M & 6 years & Positive & First-degree cousins & Another AR-CGD ${ }^{\mathrm{b}}$ & ND \\
\hline CGD-185 & M & 2 years and 3 months & Negative & None & ND & \\
\hline CGD-298 & M & 9 months & Positive & None & ND & \\
\hline
\end{tabular}

${ }^{\text {a }} \mathrm{ND}$, Not determined

b CGD-5 and 346 are in the identical pedigree, and seem to be caused by a mutation in a gene different from the known autosomal recessive CGD genes

aspects of CGD (Morel et al. 1993). Peripheral blood mononuclear cells were purified from heparinized sterile venous blood by Ficoll-Hypaque density gradient centrifugation. The cells were infected with the B95-8 EBV strain and cultured in RPMI 1640 medium supplemented with $20 \%$ foetal bovine serum and $1 \mu \mathrm{g} /$ $\mathrm{ml}$ cyclosporine A. The culture was maintained at $37^{\circ} \mathrm{C}$ under a $5 \% \mathrm{CO}_{2}$ atmosphere and the medium was changed twice weekly until autonomous growth of the derived EBV-B LCL was obtained.

\section{Isolation of DNA and RNA}

Blood samples were collected from family members of each participant after informed consent, and genomic DNA was extracted from peripheral blood leucocytes or EBV-B LCL by standard procedures. Total RNA was isolated from total blood or EBV-B LCL by use of the Trizol reagent (GibcoBRL-Life Technologies, Gaithersburg, Md.).

\section{Genotyping}

Microsatellite markers were selected from the Genethon mapping panel (Dib et al. 1996) and from physical maps available at NCBI (http://www.ncbi.nlm.nih.gov/) and Ensembl (http://www.ensembl.org/) sites. Primer pairs were synthesized for microsatellite markers suitable for homozygosity mapping at 7q11.23 (NCF1), 1q25 (NCF2), and 16q24 (CYBA). The PCR was performed in a total volume of $50 \mu \mathrm{l}$ containing $200 \mathrm{ng}$ of genomic DNA, $10 \mu M$ of each primer, $250 \mu M$ of each dNTP, $1.5 \mathrm{mM}$ of $\mathrm{MgCl}_{2}$ and $1 \mathrm{U}$ Taq DNA polymerase. The amplification buffer contained $20 \mathrm{mM}$ Tris- $\mathrm{HCl}(\mathrm{pH} 8.8)$ and $50 \mathrm{mM} \mathrm{KCl}$.

The reactions were performed using a hot-start procedure; initial denaturation was for $5 \mathrm{~min}$ at $96^{\circ} \mathrm{C}$, followed by 35 cycles of amplification with denaturation at $94^{\circ} \mathrm{C}$ for $1 \mathrm{~min}$, annealing for $1 \mathrm{~min}$ at the adequate temperature and extension at $72^{\circ} \mathrm{C}$ for $1 \mathrm{~min}$. The amplification procedure was terminated by a final extension at $72^{\circ} \mathrm{C}$ for $7 \mathrm{~min}$. The amplified products were run on a $6 \%$ polyacrylamide gel and then transferred onto a Hybond- $\mathrm{N}^{+}$membrane (Amersham Biosciences, Buckinghamshire, UK) by contact blotting procedure. Amplified fragments were visualized by hybridization at $42^{\circ} \mathrm{C}$ for $3 \mathrm{~h}$ in hybridization buffer with a radioactive-labelled poly $(\mathrm{AC})$ probe $(\mathrm{dCTP} \alpha$ $\left[{ }^{32} \mathrm{P}\right]$ ) (Hazan et al. 1992).

\section{Mutation screening}

Mutation analyses were performed on patients as well as on parents and unaffected individuals when available in order to assess the cosegregation of the mutation with the morbid phenotype.

\section{Allele-specific oligonucleotide PCR}

Initial genotyping of the $\Delta \mathrm{GT}$ mutation was determined by amplifying exon 2 of NCF1 from genomic DNA using an allele-specific oligonucleotide (ASO)- 
PCR strategy (Noack et al. 2001). PCR amplification was performed as described. The reaction products were analysed by electrophoresis on a $2 \%$ agarose gel in $0.5 \times$ TBE.

Genomic DNA amplification and direct sequencing

Exons and their flanking regions were amplified from genomic DNA. Primer pairs were generated from intron sequences to amplify the exons (primer sequences are available upon request). PCR conditions were performed as described.

PCR products were purified on QIAquick spin columns (Qiagen, Valencia, Calif.) and directly sequenced with the Big Dye Terminator kit (Applied Biosystems, Foster City, Calif.) using PCR primers as sequencing primers on an ABI Prism 377 DNA Sequencer (Applied Biosystems).

cDNA isolation, amplification and direct sequencing

In order to identify alterations at the RNA level, total RNA was isolated from total blood or EBV-B lymphocyte cell lines using of the Trizol reagent (GibcoBRL-Life Technologies). The cDNA first-strand was synthesized using the ProSTAR first-strand reversetranscriptase PCR Kit (Stratagene, La Jolla, Calif.). PCR conditions were performed as described. RTPCR products were purified and directly sequenced.

\section{Results}

Screening for $\Delta \mathrm{GT}$

The first step in our molecular analyses was to screen all the patients for the $\Delta \mathrm{GT}$ recurrent mutation occurring in the $N C F 1$ exon 2 that has been identified in multiple unrelated patients from different populations (Casimir et al. 1991; Roos et al. 1996; Ishibashi et al. 2000; Roesler et al. 2000). For this purpose we used an ASO-PCR protocol that amplified only the GTGT-containing allele (normal allele) from genomic DNA (Noack et al. 2001). Negative results on the samples following the ASO-PCR confirmed the absence of the normal sequence based on the direct sequencing of ordinarily amplified DNA segments. The $\Delta$ GT mutation in a homozygous state was confirmed in five patients, including one male patient (CGD-350) who was born to parents of a non-consanguineous marriage (Table 1).
Haplotype analyses and homozygosity mapping

Twelve patients belonging to 11 unrelated families were subjected to genotyping using markers in the flanking regions of the $N C F 1, N C F 2$ and $C Y B A$ genes to detect the apparent homozygous state. The genotype analyses revealed that the genetic defect in four patients seemed to link to $N C F 1$, in two patients to $C Y B A$ and in four patients to $N C F 2$, as the indicated area of the respective patients showed apparent homozygosity (data not shown summary in Table 1). In contrast, two patients (male CGD-346 and female CGD-5), each a child of different married couples in a large consanguineous family, clearly showed heterozygosity around the three known AD-CGD genes (Fig. 1). In this family, the involvement of a gene on $\mathrm{X}$ chromosome was excluded as the parents are apparently healthy and also have a healthy boy. Thus, the patients in the consanguineous family seemed to have developed the phenotype by (a) mutation(s) in a yet unknown AR-CGD gene.

Mutation screening

Genotyping of patient CGD-193 revealed homozygosity in a region of at least $6 \mathrm{cM}$ covering $N C F 2$. PCR amplifications of genomic DNA showed a mutation of $N C F 2$ corresponding to a $\mathrm{T}>\mathrm{C}$ transition in the conservative $5^{\prime}$-splice site of intron $3(\mathrm{IV} 3+2 \mathrm{~T}>\mathrm{C})$. The sequence in the vicinity of exon 3 is $100 \%$ identical to that published by Kenney et al. (1993), with the exception that a $\mathrm{T}$ at position +2 of the consensus $5^{\prime}$-splice site at the exon $3 /$ intron 3 boundary was substituted by $\mathrm{C}$. The mutation found in a homozygous state in patient CGD-193 was identical to that previously reported in a patient of the same ethnic origin (Tanugi-Cholley et al. 1995).

In addition, two novel mutations were identified. The first one was an $\mathrm{A}>\mathrm{T}$ single nucleotide substitution occurring at nucleotide 78 of exon 14 in NCF2, which resulted in an amino acid change from asparagine to isoleucine at codon 419 (N419I) (Fig. 2). The N419I mutation was detected in a homozygous state in a male patient (CGD-17), but not in the genome of 50 unrelated normal donors (100 chromosomes) (Fig. 2). Furthermore, the single nucleotide substitution has not been registered as a polymorphism in dbSNP at http:// www.ncbi.nlm.nih.gov/SNP/. The second novel mutation was a 7-bp deletion (295-301delGTGCCCG) in exon 5 of $C Y B A$ that resulted in a shift of the reading frame to premature termination. The mutation was detected in a homozygous state in the patient, CGD-275, and in a heterozygous state in the parents 
a 295del7
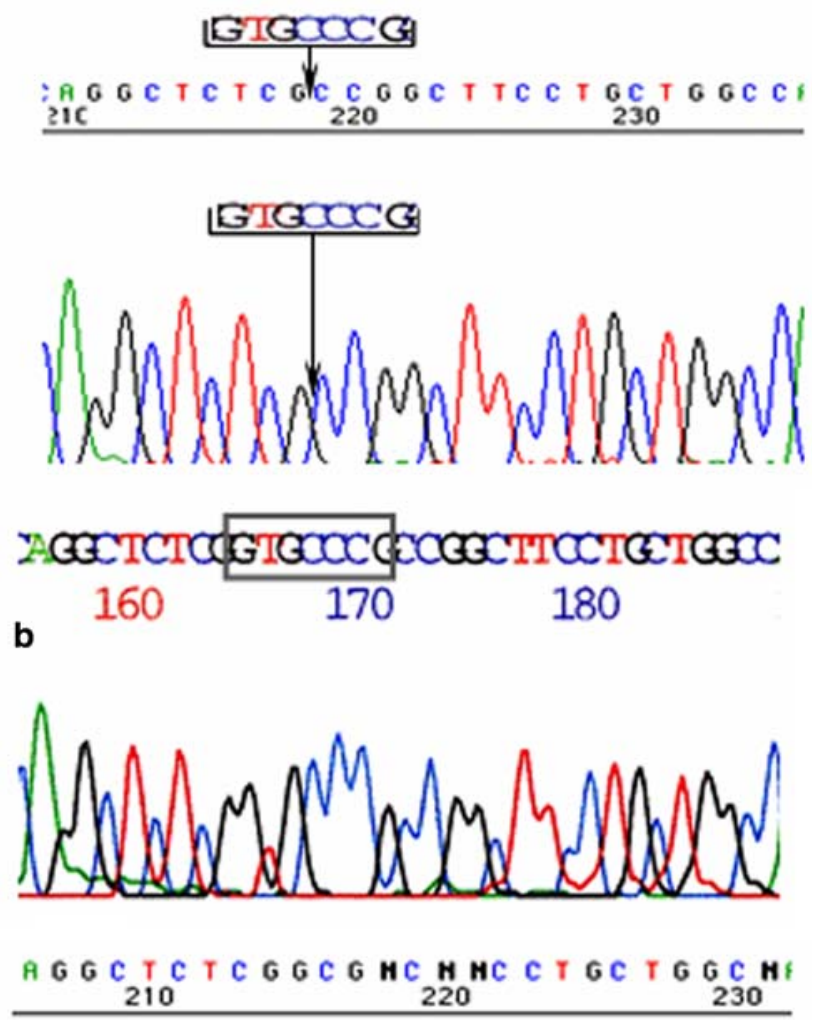

C

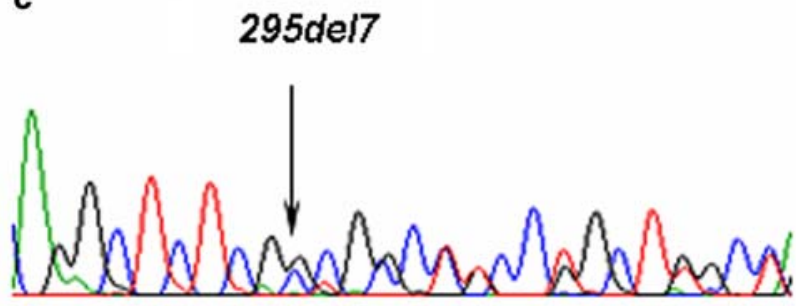

Fig. 1 Genotype analyses showing that two patients in a large consanguineous family were heterozygous around the three known AR-CGD genes. Genotypes of the CGD-5 (right) and CGD-346 (left) patients are shown with the haplotypes defined using markers flanking $N C F 2, N C F 1$ and $C Y B A$ (top to bottom). The polymorphic markers are in the order of the centromeric to telomeric direction (top to bottom), and the genotypes are indicated with the size (bp) of PCR products for each marker. Squares and circles indicate male and female members, respectively, and filled and slashed markers indicate affected and deceased members, respectively

(Fig. 3). The results of mutation analyses are summarized in Table 1 with the clinical phenotypes.

In addition to the pathogenic mutations described above, one polymorphism was detected during the course of this study, a 50-bp insertion in intron IV in $C Y B A$. This insertion (GenBank accession no. DQ781319) appeared in a homozygous state in normal family members of the investigated patients as well as in several individuals used as a control.

\section{Discussion}

According to studies carried out to date, about two thirds of all CGD cases are caused by a mutation in the $C Y B B$ gene encoding gp91phox on the $\mathrm{X}$ chromosome, thus forming the X-linked (XL) form of CGD. Mutations in the genes encoding 47 phox, p67phox and p22phox cause the autosomal recessive (AR) forms of CGD and collectively account for approximately one third of all CGD cases worldwide (Cross et al. 2000). The most common form of AR-CGD (A47 ${ }^{\circ} \mathrm{CGD}$ ) is caused by mutations in NCF1.

Unlike the other CGD subtypes in which there is a great heterogeneity among mutations (Roos et al. 1996), most of affected alleles in the patients with A $47^{\circ} \mathrm{CGD}$ carry an identical mutation - a GT deletion, $\triangle \mathrm{GT}$, at the beginning of exon 2 in $N C F 1$, which results in a frameshift that leads to translational termination by a stop codon (TAA) at amino acid position 51 (Casimir et al. 1991; Roesler et al. 2000). In our study of 15 patients living in various geographic locations in Tunisia, $30 \%(5 / 15)$ of the patients carried the $\Delta \mathrm{GT}$ mutation in NCF1. The high frequency of the $\triangle \mathrm{GT}$ mutation has been reported in multiple unrelated patients from different racial backgrounds (Roos et al. 1996). The underlying reason for the predominance of the $\Delta \mathrm{GT}$ mutation became clear when it was discovered that at least two, sometimes a few, pseudogenes are situated near the functional NCF1 gene at chromosome 7q11.23 (Görlach et al. 1997). The functional gene and pseudogenes are approximately 99\% homologous in the exonic and intronic regions, but at least one of the pseudogenes has the GT sequence instead of GTGT at the start site of exon 2 - i.e. the GT deletion. This high level of sequence homology and co-localization together with potential recombination hot spots (Alu repeats, Chi sequence and human minisatellites repeats) may result in the functional gene becoming susceptible to recombination events such as gene conversion or crossing over among the functional gene and pseudogenes (Chanock et al. 2000). Gene conversion events between homologous genes and their pseudogenes have been described in the pathogenesis of several genetic disorders, such as 21-hydroxylase deficiency (Helmberg 1993), von Willebrand disease (Eikenboom et al. 1994) and Gaucher disease (Horowitz et al. 1989). 


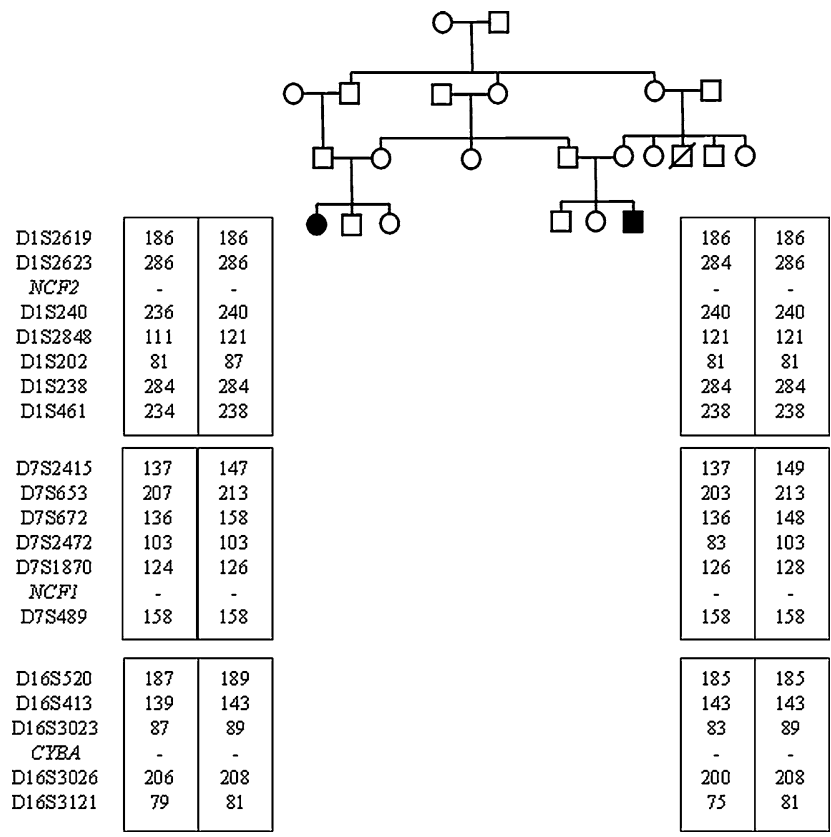

Fig. 2 Sequence profile showing a novel NCF2 mutation associated with a CGD patient. DNA segments covering the boundary of exon 14 and downstream intron of $N C F 2$ were amplified with genomic DNA from the CGD-17 patient (a) and a healthy individual (b), and the nucleotide sequences were determined. The primers used for amplification were R33F (TACAGTGGGAACCTTGTGCT) and R28R (TTGAGGAAGTGGCTCAGTGGAA), and the R33F primer was used for sequencing following purification of the amplified products. The A1256T nucleotide substitution (arrow) resulted in amino acid substitution of N419I

Among the 12 patients from the 11 unrelated families, homozygosity mapping showed that CGD in four patients is linked to $N C F 1$, with all of these patients having the NCF1 $\triangle \mathrm{GT}$ deletion. For the eight remaining patients, haplotype analysis showed that four patients were homozygous for the markers closely linked to NCF2 and two patients were homozygous for the markers closely linked to $C Y B A$. Two patients born in a consanguineous family (CGD-5 and CGD$346)$ were heterozygous for markers linked to $N C F 1$ as well as for markers of $N C F 2$ and $C Y B A$. Thus, the two affected children in the large pedigree did not inherit the identical chromosomes carrying these AR-CGD genes. This is not consistent with the generally accepted principle that in recessively inherited, rare diseases, affected children from a consanguineous family are expected to be homozygous at the defective allele inherited from a common ancestor and for the genetic interval encompassing the causative gene (Lander and Botstein 1987). The CGD of two patients is probably due to a defect on a gene other than the known AR-CGD genes.
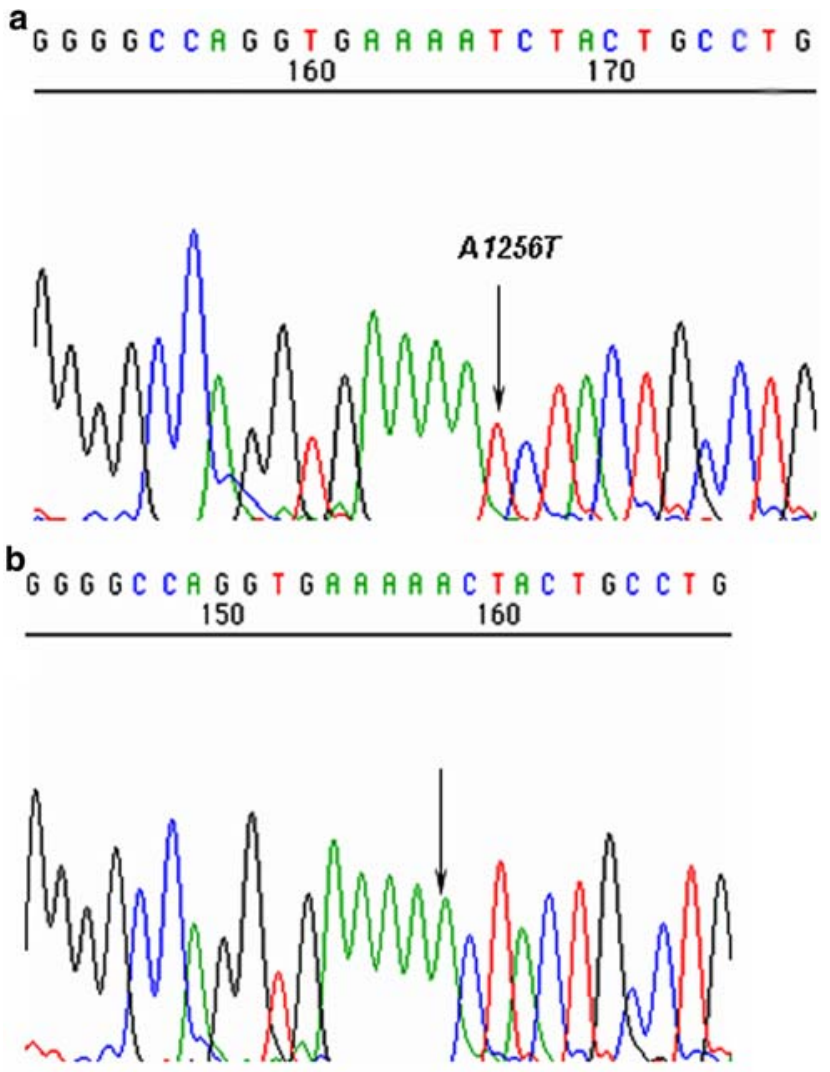

Fig. 3 Sequence profile showing a novel deletion in $C Y B A$ associated with a CGD patient. DNA segments covering the boundary of exon 5 and downstream intron of $C Y B A$ were amplified with genomic DNA from the CGD-275 patient (a), a healthy individual (b) and one of the parents of the patient (c), and the nucleotide sequences were determined. The primers used for amplification were Y9F (GCTAGTGTCCACATCAAGGCTGA) and Y10R (ACCAGTAGGTAGAT GCCGCT), and the primer Y9F was used for sequencing. The sequence of GTGCCCG (boxes) was deleted in the patient. Each of the parents were confirmed to be a heterozygous carrier for the deletion, although only one of the parents is shown here

The genotyping of a male patient (CGD-193) revealed a homozygous region of $6 \mathrm{cM}$ covering $N C F 2$. Sequence analyses of the genomic DNA of the CGD193 patient showed a $\mathrm{T}>\mathrm{C}$ transition at position +2 of intron 3. It is worth noting that this mutation has already been described in a North African patient suffering from a p67phox-deficient form of CGD (Tangui-Cholley et al. 1995). Based on the exonic organization of NCF2 (Kenny et al. 1993), TanguiCholley et al. inferred that the mutation in the splice site at the beginning of intron 3 is responsible for the skipping of exon 3. The consequence is a transitional -1 frameshift after codon 58, which generates a premature TGA stop codon at position 60 . 
Screening for mutations in CGD genes led us to identify two novel mutations in a homozygous state in two unrelated CGD patients. The first is a single nucleotide change $(\mathrm{A}>\mathrm{T})$ at nucleotide 78 of exon 14 in $N C F 2$ which predicts a non-conservative asparagine to isoleucine substitution at residue 419 (N419I) of the encoded protein. Fifty unrelated individuals from the general population screened negative for the $\mathrm{A}>\mathrm{T}$ substitution, thereby confirming that this mutation was not a polymorphism. The asparagine 419 to isoleucine substitution was detected in the C-terminal PB1 domain of p67phox that is involved in the interaction with p40phox. The interaction between p40phox and p67phox, via the PB1 domains, leads to enhanced membrane translocation of cytosolic subunits in stimulated cells, resulting in increased NADPH oxidase activity. Of special interest is the one point mutation, R395W, within the p67phox PB1 domain, which affects NADPH oxidase activity; this point mutation has been reported in two patients with severe CGD (Noack et al. 1999). Our findings strongly suggest that a replacement of asparagine for isoleucine at residue 419 results in a non-functional phagocyte oxidase and CGD and, consequently, identify one critical amino acid residue in the p67phox protein.

The second novel mutation, also detected in a male patient (CGD-275) was a 7-bp deletion of the sequence in the exon 5 of $C Y B A$, which predicts a frameshift and a premature termination of p22phox synthesis. Both parents were found to be heterozygous for this mutation. The 295-301del7 mutation was found to be flanked by CCTG motifs and TTC direct repeats, both of which have previously been identified to be mutation hot-spot consensus sequences for, in particular, spontaneous small deletions ( $<20 \mathrm{bp}$ ) (Krawczak and Cooper 1991; Smith and Adair 1996). In addition to the CCTG motif and the TTC direct repeats, this deletion was surrounded by the highly GC-rich region; such regions have frequently been identified at the site of human DNA deletions (Krawczak and Cooper 1991).

In patient CGD-275 we also found a 50-bp insertion in intron IV in $C Y B A$. This insertion appeared in the homozygous state in both normal controls and in family members of the patients of this study. This insertion proved to be a 50-bp repeat, probably caused by unequal crossing over during meiosis. We therefore suggest that the insertion is a benign variant and not a cause of the CGD syndrome.

Consistent with previous studies of mutations causing XL-CGD and AR-CGD (NCF2 and CYBA), our results show a variety of defects, deletions, missense and splice site mutations. Carriers of the AR forms of CGD can be difficult to detect as they typically have a normal NBT slide test and have rates of $\mathrm{O}_{2}^{-}$production within the normal range. The identification of mutations in individuals with autosomally inherited forms of CGD provides the only effective basis for detecting carriers among family members or performing prenatal diagnosis.

In our study, only two patients (CGD-185 and CGD$298)$ among $15(13,33 \%)$ are likely to be XL-CGD. This result is specific to our population as the most common form of CGD reported in other studies is the XL form (Dinauer et al 1987). To our knowledge, this investigation is the first genetic and molecular analysis of CGD in the Maghreb region and, specifically, in Tunisia.

The North African population is characterized by a high degree of consanguinity despite its various ethnic backgrounds. In Tunisia, the rate of consanguineous marriages is estimated to be $33 \%$, reaching over $60 \%$ depending on the area studied (Riou et al. 1989). This very high incidence of consanguinity is based on the fact that endogamy is a culturally favoured custom (Khlat 1997). As a direct result of the high rate of inbreeding, there is an increase in the prevalence of recessive genetic disorders (Hoodfar and Teebi 1996). This may explain the relatively high prevalence of AR forms of CGD in Tunisia. This study further confirms usefulness of classifying patients by homozygosity mapping for genetically heterogeneous AR disorders.

We have already demonstrated the usefulness of homozygosity mapping for several disorders, i.e. idiopathic immuno-deficiency (Elloumi-Zghal et al. 2002) and Fanconi anemia (Bouchlaka et al. 2003). This strategy is particularly reliable in informative families originating from populations with a particular familial structure - i.e. large size of sibships born to consanguineous mating. Genotyping with microsatellite markers provides an indirect, rapid and cost-effective tool for the molecular investigation of genetically heterogeneous diseases in populations where endogamy is culturally favoured.

Acknowledgements We gratefully acknowledge the cooperation of the patients and their families during this study. This work was funded by the Tunisian Ministry for Scientific and Technological Research and Development of Competencies.

\section{References}

Ahlin A, de Boer M, Roos D, Leusen J, Smith CIE, Sundin U, Rabbani H, Palmbald J, Elinder G (1995) Prevalence, genetics and clinical presentation of chronic granulomatous disease in Sweden. Acta Paediatr 84:1386-1394

Babior BM (1999) NADPH oxidase: an update. Blood 93:1464-1476 
Baehner RL, Nathan DG (1967) Leukocyte oxidase: defective activity in chronic granulomatous disease. Science 155:835836

Barbouche MR, Sghiri R, Mellouli F, Boukhdir Y, Dellagi K, Bejaoui M (1999) Chronic septic granulomatous disease: 14 cases. Presse Med 28:2034-6

Bouchlaka C, Abdelhak S, Amouri A, Ben Abid H, Hadiji S, Frikha M, Ben Othman T, Amri F, Ayadi H, Hachicha M, Rebai A, Saad A, Dellagi K, Tunisian Fanconi Anemia Study Group (2003) Fanconi anemia in Tunisia: high prevalence of group A and identification of new FANCA mutations. J Hum Genet 48:352-361

Casimir CM, Bu-Ghanim HN, Rodaway AR, Bentley DL, Rowe P, Segal AW (1991) Autosomal recessive chronic granulomatous disease caused by deletion at a dinucleotide repeat. Proc Natl Acad Sci USA 88:2753-2757

Chanock SJ, Roesler J, Zhan S, Hopkins P, Lee P, Barrett DT, Christensen BL, Curnutte JT, Gorlach A (2000) Genomic structure of the human p47-phox (NCF1) gene. Blood Cells Mol Dis 26:37-46

Clark RA, Malech HL, Gallin JI, Nunoi H, Volpp BD, Pearson DW, Nauseef WM, Curnutte JT (1989) Genetic variants of chronic granulomatous disease: prevalence of deficiencies of two cytosolic components of the NADPH oxidase system. N Engl J Med 321:647-652

Cross AR, Noack D, Rae J, Curnutte JT, Heyworth PG (2000) Hematologically important mutations: the autosomal recessive forms of chronic granulomatous disease (first update). Blood Cells Mol Dis 26:561-565

Dib C, Faure S, Fizames C, Samson D, Drouot N, Vignal A, Millasseau P, Marc S, Hazan J, Seboun E, Lathrop M, Gyapay G, Morissette J, Weissenbach J (1996) A comprehensive genetic map of the human genome based on 5,264 microsatellites. Nature 380:152-154

Dinauer MC, Orkin SH (1992) Chronic granulomatous disease. Annu Rev Med 43:117-124

Dinauer MC, Orkin SH, Brown R, Jesaitis AJ, Parkos CA (1987) The glycoprotein encoded by the X-linked chronic granulomatous disease locus is a component of the neutrophil cytochrome $b$ complex. Nature 327:717-720

Eikenboom JC, Vink T, Briet E, Sixma JJ, Reitsma PH (1994) Multiple substitutions in the von Willebrand factor gene that mimic the pseudogene sequence. Proc Natl Acad Sci USA 91:2221-2224

Elloumi-Zghal H, Barbouche MR, Chemli J, Bejaoui M, Harbi A, Snoussi N, Abdelhak S, Dellagi K (2002) Clinical and genetic heterogeneity of inherited autosomal recessive susceptibility to disseminated Mycobacterium bovis bacille calmette-guerin infection. J Infect Dis 185:1468-1475

Gorlach A, Lee PL, Roesler J, Hopkins PJ, Christensen B, Green ED, Chanock SJ, Curnutte JT (1997) A p47-phox pseudogene carries the most common mutation causing p47phox- deficient chronic granulomatous disease. J Clin Invest 100:1907-1918

Hazan J, Dubay C, Pankowiak M P (1992) A genetic linkage map of human chromosome 20 composed entirely of microsatellite markers. Genomics 12:183-189

Helmberg A (1993) Twin genes and endocrine disease: CYP21 and CYP11B genes. Acta Endocrinol 129:97-108

Heyworth PG, Bohl BP, Bokoch GM, Curnutte JT (1994) Rac translocates independently of the neutrophil NADPH oxidase components p47phox and p67phox. Evidence for its interaction with flavocytochrome $b_{558}$. J Biol Chem 269:30749-30752
Hoodfar E, Teebi AS (1996) Genetic referrals of Middle Eastern origin in a western city: inbreeding and disease profile. $\mathbf{J}$ Med Genet 33:212-215

Horowitz M, Wilder S, Horowitz Z, Reiner O, Gelbart T, Beutler E (1989) The human glucocerebrosidase gene and pseudogene: structure and evolution. Genomics 4:87-96

Ishibashi F, Nunoi H, Endo F, Matsudal, Kanegasaki S (2000) Statistical and mutation al analysis of chronic granulomatous disease in Japan with special reference to gp91-phox and p22-phox deficiency. Hum Genet 106:473-481

Kenney RT, Malech HL, Epstein ND, Roberts RL, Leto TL (1993) Characterization of the p67phox gene: genomic organization and restriction fragment length polymorphism analysis for prenatal diagnosis in chronic granulomatous disease. Blood 82:3739-3744

Khlat M (1997) Endogamy in the Arab word. In: Teebi AS, Farag TI (eds) Genetic disorder among Arab populations. Oxford University Press, New York, pp 63-80

Knaus UG, Heyworth PG, Evans T, Curnutte JT, Bokoch GM (1991) Regulation of phagocyte oxygen radical production by the GTP-binding protein Rac 2. Science 254:1512-1515

Krawczak M, Cooper DN (1991) Gene deletions causing human genetic disease: mechanisms of mutagenesis and the role of the local DNA sequence environment. Hum Genet 86:425441

Kwong CH, Malech HL, Rotrosen D, Leto TL (1993) Regulation of the human neutrophil NADPH oxidase by rho-related Gproteins. Biochemistry 32:5711-5717

Lander ES, Botstein D (1987) Homozygosity mapping: a way to map human recessive traits with the DNA of inbred children. Science 236:1567-1570

Morel F, Cohen Tanugi Cholley L, Brandolin G, Dianoux AC, Martel C, Champelovier P, Seigneurin JM, Francois P, Bost M, Vignais PV (1993) The $\mathrm{O}_{2}^{-}$generating oxidase of $\mathrm{B}$ lymphocytes: Epstein-Barr virus-immortalized B lymphocytes as a tool for the identification of defective components of the oxidase in chronic granulomatous disease. Biochim Biophys Acta 1182:101-109

Noack D, Rae J, Cross AR, Munoz J, Salmen S, Mendoza JA, Rossi N, Curnutte JT, Heyworth PG (1999) Autosomal recessive chronic granulomatous disease caused by novel mutations in NCF-2, the gene encoding the p67-phox component of phagocyte NADPH oxidase. Hum Genet 105:460467

Noack D, Rae J, Cross AR, Ellis BA, Newburger PE, Curnutte JT, Heyworth PG (2001) Autosomal recessive chronic granulomatous disease caused by defects in $N C F-1$, the gene encoding the phagocyte p47-phox: mutations not arising in the NCF-1 pseudogenes. Blood 97:305-311

Riou S, El Younsi C., Chaabouni H (1989) Consanguinité dans la population du nord de la Tunisie. Tun Med 67:167-172

Roesler J, Curnutte JT, Rae J, Barrett D, Patino P, Chanock SJ, Goerlach A (2000) Recombination events between the p47phox gene and its highly homologous pseudogenes are the main cause of autosomal recessive chronic granulomatous disease. Blood 95:2150-2156

Roos D, de Boer M, de Klein A, Bolscher BGJM, Weening RS (1993) Chronic granulomatous disease: mutations in cytochrome b558. Immunodeficiency 4:289-301

Roos D, de Boer M, Kuribayashi F, Meischl C, Weening RS, Segal AW, Ahlin A, Nemet K, Hossle JP, BernatowskaMatuszkiewicz E, Middleton-Price H (1996) Mutations in the $\mathrm{X}$-linked and autosomal recessive forms of chronic granulomatous disease. Blood 87:1663-1681 
Royer-Pokora B, Kunkel LM, Monaco AP, Goff SC, Newburger PE, Baehner RL, Cole FS, Curnutte JT, Orkin SH (1986) Cloning the gene for an inherited human disorder chronic granulomatous disease on the basis of its chromosomal location. Nature 322:32-38

Smith DG, Adair GM (1996) Characterization of an apparent hotspot for spontaneous mutation in exon 5 of the Chinese hamster APRT gene. Mutat Res 352:87-96

Tanugi-Cholley LC, Issartel JP, Lunardi J, Freycon F, Morel F, Vignais PV (1995) A mutation located at the $5^{\prime}$ splice junction sequence of intron 3 in the p67-phox mRNA in a patient with chronic granulomatous disease. Blood 85:242-249
Tsunawaki S, Mizunari H, Nagata M, Tatsuzawa O, Kuratsuji T (1994) A novel cytosolic component, p40phox, of respiratory burst oxidase associates with p67phox and is absent in patients with chronic granulomatous disease who lack p67phox. Biochem Biophys Res Commun 199:1378-1387

Wientjes FB, Hsuan JJ, Totty NF, Segal AW (1993) p40phox, a third cytosolic component of the activation complex of the NADPH oxidase to contain src homology 3 domains. Biochem J 296:557-561 